\title{
EESTI PASSIIV JA IMPERSONAAL XVII-XVIII SAJANDI PIIBLITÕLKIJATE PILGU LÄBI
}

\author{
ANNIKA KILGI
}

\section{Sissejuhatus}

$\Omega$ eekond 1640. aastate tõlketalgutest esimese eestikeelse täispiiblini kestis umbes sajandi. Selle aja jooksul valmis kümmekond Uue Testamendi (UT) redaktsiooni: käsikirju, kirikukäsiraamatutes avaldatud katkendeid ning eraldi raamatuna välja antud UT tõlkeid. Vana Testament (VT) tõlgiti esmapiibli jaoks märksa lühema ajaga, 1720.-1730. aastatel, ning seni teada olevalt ei kasutatud seejuures ei Johannes Gutslaffi ega Virginiuste osalisi VT tõlkeid.

Enim valmistasid tõlkijatele ilmselt peavalu kohad, kus lähte- ja sihtkeele grammatiline süsteem erinesid. Üks niisuguseid valdkondi, mille üle eesti keelde tõlkija paratamatult mõtisklema peab, on passiivsuse ja impersonaalsuse väljendamine. Siinses artiklis püüangi välja selgitada, 1) kas ja kuidas muutus sajandi jooksul passiivsete ja impersonaalsete vormide tarvitus, ning 2) kas UT ja VT vahel on erinevusi, mis võiksid olla tingitud nende erinevast tõlkeloost.

Selleks võrdlen kuutteist Uue ja kolme Vana Testamendi versiooni, mille loend on lisas. Lisast leiab ka info selle kohta, kui palju neis üht või teist keelendit leidub. Uuest Testamendist vaatlen Luuka evangeeliumi ning Vanast Testamendist 1 . Moosese raamatu 35 esimest peatükki. Otsin sealt kaht peamist eesti tegumoevahendit: impersonaali ja seisundipassiivi. Peale nende iseloomustan ka saama-passiivi ja toon umbisikulistest vormidest eraldi välja $m a$-tegevusnime impersonaali, mida tollased piiblitõlkijad palju tarvitasid. Ülejäänud passiivseid ja impersonaalseid konstruktsioone (nt seisab tehtud) esines harva ja need jäävad siin kirjeldamata. Artikkel iseloomustab seega järgnevate keelendite kasutamise dünaamikat:

- ühemõtteliselt umbisikulised finiitvormid: leitakse, leiti, ei leita jt;

- olema ja tud-kesksõna ühendid: on leitud, olid leitud, ei oleks leitud jt (seisundipassiivi vormidest ei ole püütud eristada võimalikke kokkulangevusi impersonaali liitminevikuvormidega; selliste ühendite passiiviks või impersonaaliks klassifitseerimise raskuste ja võimalike lahenduste kohta vt nt Rajandi 1999: $63 \mathrm{jj}$ );

- saama ja tud-kesksõna ühendid: saab leitud, sai leitud, saagu leitud jt;

- ühendid ma-tegevusnime impersonaaliga: saab leitama, peab leitama.

Selgitamaks välja, mis võis olla nende vormide peamiseks eeskujutekstiks ja/või -keeleks, kõrvutan leitud keelendeid järgnevate oluliste piibliversiooni- 
dega: 1) Uue Testamendi kreekakeelse originaaliga,millest kasutan varianti Textus Receptus (edaspidi lühend kr-TR); 2) Vana Testamendi heebreakeelse originaali Tanahiga (hbr-T); 3) ladina tõlke Vulgataga (ld-V) ning 4) Martin Lutheri piiblitõlkega (sks-L).

\section{Passiivsuse tõlkimise taust}

\subsection{Passiivsed ja impersonaalsed keelendid lähte- ja sihtkeeles}

Eesti keeles on olemas nii personaali ja impersonaali kui ka aktiivi ja passiivi vastandus. Passiivis nihkub esiplaanile tegevusobjekt: aktiivse lause sihitis saab aluseks (nt sulgesin ukse > uks on suletud). Impersonaali eesmärk seevastu on tegija ebamääraseks jätmine. Et tegevusobjekti ei pruugita seejuures aluseks teha, esinevad umbisikulised vormid ka intransitiivsetel verbidel (nt elasin Tallinnas > Tallinnas elati) (Erelt jt 2007: 453, 455). Impersonaali peetakse eesti keelele omaseks vormiks, personaalset seisundipassiivi seevastu indoeuroopa kesksõnaliste passiivide eeskujul tekkinud uuenduseks (Torn-Leesik 2009: 72). Peale nende kahe põhilise tegumoekonstruktsiooni on eesti keeles ka teisi passiivsuse ja impersonaalsuse väljendamise võimalusi, nt saama + tud-kesksõna, olema $+d a$-tegevusnimi ja ainsuse 3. pööre (laud saab kaetud, see on mulle teada, selle töö teeb natukese ajaga valmis) (Erelt jt 1993: 30-31).

XVII-XVIII sajandil piiblit eesti keelde tõlkides kasutati lähtetekstina nii saksakeelset Martin Lutheri tõlget kui ka heebrea- ja kreekakeelset originaali. Lisaks on tõlgetes kohati tajutav ladinakeelse Vulgata mõju (vt nt Ross 2006). Need neli keelt olid küllap hästi tuttavad tollastele eesti kirjakeele kujundajatele, kelleks olid enamjaolt teoloogiaharidusega pastorid.

Vanakreeka verbil on kolm tegumoodi: aktiiv, meedium ja passiiv. Passiiv on isikuline, osutades tegevuse objektile. Meedium langeb küll vormilt peaaegu alati passiiviga kokku (v.a aoristis ja futuurumis), kuid väljendab teistsugust tähendust: enesekohasust või subjekti isiklikku huvitatust tegevusest (Tamm 1991: 38). Näiteks verbist $\varepsilon v \delta v ́ \omega$ 'riidesse panema' saab moodustada

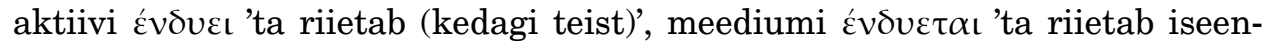

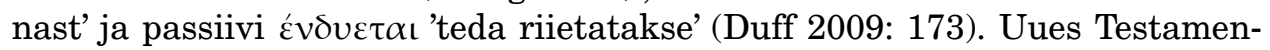
dis esineb sageli ka depoonensverbe, millel puuduvad aktiivi vormid, ent mille passiivi ja meediumi vorme kasutatakse aktiivses tähenduses (Unt 1998: 43). Vanakreeka keeles on võimalik väljendada ka umbisikulisust, tehes seda kas passiivi ainsuse kolmanda või aktiivi mitmuse kolmanda pöördega (Unt 1998: 39).

Ladina verbil on kaks tegumoodi: aktiiv ja passiiv. Transitiivsete verbide passiiv on isikuline, intransitiivsete oma umbisikuline. Intransitiivsete verbide passiivis on võimalik kasutada ainult kolmandat pööret, nt vivitur 'elatakse' (Lill jt 2002: 150). Nagu kreeka keeleski on ladina keeles olemas depoonensverbid, mil puuduvad aktiivi vormid, kuid mille passiivi vormidel on aktiivi tähendus. Pooldepoonensverbide kõigi vormide tähendus on samuti aktiivne, kuid osa aegu moodustatakse aktiivis ja osa passiivis (Lill jt 2002: 183).

Heebrea verbil on traditsioonilise käsitluse kohaselt seitse põhikonjugatsiooni ja harvemaid konjugatsioone, mis väljendavad sama tüve tähendus- 
varjundeid. Tegumoode on kolm: aktiiv ('Taavet võitis vaenlase'), passiiv ('Taavet võideti vaenlase poolt') ja refleksiiv ('Taavet pani end riidesse'). Samuti on kolm põhilist verbi tegevuse kategooriat: lihtne ('purunema'), intensiivne ('tükkideks purunema') ja kausatiivne ('purustama') (Waltke, O'Connor 1990: 354, 358-360). Seitsmest põhikonjugatsioonist ${ }^{1}$ väljendavad passiivset tähendust neli: nif'al on lihtne passiiv või refleksiiv, pu'al intensiivne passiiv, huf'al kausatiivne passiiv (Kelley 1992: 108) ja intensiivtüve refleksiivkonjugatsioon hitpa'el võib samuti väljendada passiivset tähendust (Kross 1985: 40). Lisaks esineb harva eesmärgitüve passiivi po'al (Kross 1985: 41). Impersonaalselt on võimalik kasutada väheseid verbe, nt tašəlēg bəșalamwōn 'Salmonil sadas'. Enamasti kasutatakse sel puhul pa'al-tüve (Waltke, O'Connor 1990: 376).

Saksa verbil on aktiiv ja kaks passiivi, millest ühes on abitegusõnaks werden 'saama' ja teises sein 'olema'. Werden-passiiv väljendab protsessi või tegevust, sein-passiiv tegevuse tulemusena tekkinud seisundit. Peale passiivi on saksa keeles ka arvukalt passiivse tähendusega aktiivseid konstruktsioone, nt bleiben + II partitsiip (Das Fenster bleibt geöffnet 'aken jääb avatuks') ja es gibt $+z u+$ infinitiiv (Es gibt hier viele Bücher zu lesen 'siin on palju raamatuid lugeda') (Helbig, Kempter 1997: 7, 54). Passiiv moodustatakse peaaegu alati transitiivsetest verbidest, mille aktiivi lauses olev sihitis saab passiivses lauses olla aluseks. Passiivi saab moodustada vaid mõnest üksikust intransitiivsest verbist ning sel juhul on tegu nn umbisikulise passiiviga, nt Es wurde viel darüber gelacht 'Selle üle naerdi palju' (Hoberg, R., Hoberg, U. 1997: 68-72). Umbisikulisust saab väljendada ka sõnaga man, mis viitab määratlemata tegijale, nt Man öffnete die Tür 'uks avati' (Helbig, Kempter 1997: 54).

Niisiis on kõigis nimetatud keeltes olemas võimalused väljendada nii passiivsust kui ka impersonaalsust, kuid need erinevad üksteisest üsna palju. Kõige silmatorkavam erinevus on, et piiblitõlkimise lähtekeeltes (kreeka, heebrea, ladina, saksa) puuduvad eesti verbile omased impersonaalivormid.

\subsection{Passiiv ja impersonaal esimestes eesti keele grammatikates}

Täispiibli vormumise aegsed grammatikad olid tõlketööga tihedalt seotud ning annavad hea ettekujutuse sellest, kuidas tollased piiblitõlkijad sihtkeele grammatilist süsteemi tajusid. Grammatika andsid välja esimeste põhjaeestikeelsete kirikuraamatute üllitaja Heinrich Stahl (1637), oma piiblitõlke koostanud Johannes Gutslaff (1648), 1687. aasta Pilistvere piiblikonverentsil aluseks võetud käsikirja koostaja Heinrich Göseken vanem (1660), üks XVII sajandi lõpu keelereformaatoreid Johann Hornung (1693) ning täispiibli keelele lõpliku kuju andnud seltskonna üks suurimaid keeleautoriteete Anton Thor Helle (1732).

Eesti passiivi vormidena kirjeldasid esimese kolme grammatika autorid Heinrich Stahl, Johannes Gutslaff ja Heinrich Göseken tud-kesksõna ühendeid tegusõnadega saama ja olema, esitades seega paralleelid nii saksa werden-passiivile (saama + tud-kesksõna) kui ka sein-seisundipassiivile (olema + tud-kesksõna). Abiverbid olid komplementaarses distributsioonis: olema abil moodustati eesti indikatiivi perfekt ja pluskvamperfekt, saama abil

1 On ka neid (nt Brettler 2002: 176, 260), kelle meelest on heebrea keeles viis põhikonjugatsiooni, sest pu'al on pi'el'i passiiv ja huf'al hif'il'i passiiv. 
indikatiivi preesens, imperfekt ja futuurum, samuti ülejäänud kõneviiside vormid.

Järgmistes grammatikates jätsid Johann Hornung ja Anton Thor Helle passiivi paradigmasse püsima küll olema + tud-kesksõna, kuid asendasid saa$m a$-ühendid indikatiivis vormidega, mida tänapäevane eesti keele kirjeldus nimetab impersonaaliks: leitakse, leiti, ei leita, ei leitud. Ülejäänud kõneviisides jäi abiverbiks saama: saagu leitud, saaks leitud jne.

Eesti keele verbide impersonaliseerimisvõimalusest olid teadlikud siiski ka kolme esimese grammatika autorid, keda ilmselt segas niisuguseid vorme paradigmasse hõlmamast nende sisuline erinevus passiivist. Juba esimese grammatika autor kirjutas: „Eestlastel on ka personaalsed ja impersonaalsed verbid. Personaalsed on omakorda kas aktiivsed või passiivsed.... Impersonaalsetel verbidel pole muud kui indikatiivi preesens ja imperfekt" (Stahl 1637: 9-10).

Järgmises grammatikas pühendas Johannes Gutslaff sellele teemale terve lehekülje, tehes vahet verbidel, mis on impersonaalsed a) alati, nt jôhus 'juhtub' ja neuwus 'näib'; või b) mõnikord, nt kulus 'kuulukse', söti 'söödi' ja sai sötus 'oli saanud söödud' (Gutslaff 1648 [1998]: 169). Teises kohas, nimelt passiivi iseloomustades kirjeldas Gutslaff ka impersonaalivormide moodustamist, nimetades seda aga ainsuse kolmanda pöörde vormide moodustamiseks (küllap toetas niisugust tõlgendust saksa man-tarind, kus umbmäärase asesõna man kõrval just seda verbivormi kasutatakse): „Indikatiivi preesensi singulari kolmas isik, nagu ka tema imperfekti singulari ainsuse kolmas isik luuakse analoogiliselt; preesensis muutub ma tas-iks, nagu: Oppetas 'õpetatakse', Temma pessetas 'pekstakse'; imperfektis aga muutub infinitiivi ma ti-ks, nagu: Temma oppeti 'õpetati', pesseti 'peksti' jne" (Gutslaff 1648 [1998]: 119)

Kolmandas, Gösekeni grammatikas, esitatakse vahetult passiivivormistiku järel ka impersonaalide loetelu, kusjuures vorme sü̈̈akse, üteldakse, kirjutakse, hüütakse, söödetakse (sks 'man isset', 'man saget' jne) nimetatakse impersonaalsete verbide aktiiviks ja vorme söödi, joodi, jagati, pillati, mateti ja kisuti (sks 'es ward gegessen', 'es ward getruncken' jne) impersonaalsete verbide passiiviks (Göseken 1660: 41).

Mõningast nõutust impersonaali ja passiivi suhestamisel aimub kõigist grammatikatest, ka Hornungil ja Thor Hellel, kes olid impersonaalsed vormid hõlmanud paradigmasse, s.t tundub, et nad pidasid umbisikulisi vorme moodustatavaks kõigist sõnadest, mitte üksikutest impersonaalsetest verbidest. Ometi esitasid nemadki näidisvormistikud üksnes transitiivsetest verbidest ja koos isikuliste asesõnadega (v.a Thor Helle minema), rõhutades nõnda passiivile omast tegevusobjekti, mis impersonaalis ilmtingimata vajalik ei ole. Thor Helle (1732: 28) juhib siiski tähelepanu neutraalsete ehk intransitiivsete verbide impersonaliseerimise võimalusele: „Neutraalseid verbe kasutatakse ka passiivselt, kui kõneldakse impersonaalselt, näiteks siit minnakse 'hier geht man durch', ei siin käida 'man geht hier nicht'." 
Indikatiivi passiivi vormistik esimestes eesti keele grammatikates ${ }^{2}$

\begin{tabular}{|l|l|l|l|l|l|}
\hline $\begin{array}{l}\text { Kirjel- } \\
\text { dus }\end{array}$ & Stahl 1637 & Gutslaff 1648 & Göseken 1660 & $\begin{array}{l}\text { Hornung } \\
\mathbf{1 6 9 3}\end{array}$ & Thor Helle 1732 \\
\hline preesens & $\begin{array}{l}\text { mina saan leitud 'ich } \\
\text { werde gefunden' }\end{array}$ & $\begin{array}{l}\text { mina saa leitud } \\
\text { 'invenior' }\end{array}$ & $\begin{array}{l}\text { mina saan } \\
\text { leitud }\end{array}$ & mind leitakse & $\begin{array}{l}\text { mind leitakse 'ich werde } \\
\text { gefunden' }\end{array}$ \\
\hline $\begin{array}{l}\text { im- } \\
\text { perfekt }\end{array}$ & $\begin{array}{l}\text { mina sain leitud 'ich } \\
\text { ward gefunden' }\end{array}$ & $\begin{array}{l}\text { mina sai leitud } \\
\text { 'inveniebar' }\end{array}$ & $\begin{array}{l}\text { mina sain } \\
\text { leitud }\end{array}$ & mind leiti & $\begin{array}{l}\text { mind leiti 'ich wurde } \\
\text { gefunden' }\end{array}$ \\
\hline perfekt & $\begin{array}{l}\text { mina olen leitud 'ich } \\
\text { bin gefunden worden' }\end{array}$ & $\begin{array}{l}\text { mina ole leitud } \\
\text { 'inventus sum' }\end{array}$ & $\begin{array}{l}\text { mina olen } \\
\text { leitud }\end{array}$ & $\begin{array}{l}\text { mina olen } \\
\text { leitud/ mind } \\
\text { on leitud }\end{array}$ & $\begin{array}{l}\text { mina olen leitud/ mind } \\
\text { on leitud 'ich bin } \\
\text { gefunden worden' }\end{array}$ \\
\hline $\begin{array}{l}\text { plus- } \\
\text { kvam- } \\
\text { perfekt }\end{array}$ & $\begin{array}{l}\text { mina olin leitud 'ich } \\
\text { war gefunden worden' } \\
\text { futuu- } \\
\text { rum }\end{array}$ & $\begin{array}{l}\text { mina saan leitud saama } \text { olin } \\
\text { 'inventus eram' } \\
\text { ich werde gefunden } \\
\text { leitud/ mind } \\
\text { oli leitud }\end{array}$ & $\begin{array}{l}\text { mina olin leitud/ mind oli } \\
\text { leitud 'ich war gefunden } \\
\text { worden' }\end{array}$ \\
\hline
\end{tabular}

See, et esimesed kolm grammatikut kasutasid passiivis rohkem saamaühendeid ja järgmised kaks umbisikulist tegumoodi, ilmnes ka infiniitvormide kirjeldusest (vt tabelit 2). Kõik loetlesid infiniitvormide hulgas tud-kesksõna, kuid ainult kolme esimese grammatika koostajad paigutasid sinna ka leitud saama ja saama leitud saama ja ainult kahe järgmise grammatika autorid $m a$-tegevusnime impersonaali leitama ja tav-kesksõna leitav.

Tabel 2 .

\section{Passiivi infiniitvormid esimestes eesti keele grammatikates}

\begin{tabular}{|c|c|c|c|c|}
\hline Stahl 1637 & Gutslaff 1648 & Göseken 1660 & Hornung 1693 & Thor Helle 1732 \\
\hline $\begin{array}{l}\text { - leitud saama } \\
\text { 'gefunden werden' } \\
\text { - kes saab leitud } \\
\text { saama 'der da wird } \\
\text { gefunden werden' } \\
\text { - leitud 'gefunden } \\
\text { worden' } \\
\text { - leitud olla } \\
\text { 'gefunden worden } \\
\text { sein' }\end{array}$ & $\begin{array}{l}\text { - leitud saama } \\
\text { 'inveniri' } \\
\text { - saama leitud } \\
\text { saama 'inveni- } \\
\text { endum esse' } \\
\\
\text { - leitud olema } \\
\text { 'inventum esse' }\end{array}$ & $\begin{array}{l}\text { - leitud saama } \\
\text { - kes saab } \\
\text { leitud saama } \\
\text { - leitud } \\
\text { - leitud olla }\end{array}$ & $\begin{array}{l}\text { - leitud 'der da gefunden } \\
\text { ist' } \\
\text { - olema leitud 'gefunden } \\
\text { sein' } \\
\text { - leitama 'gefunden } \\
\text { werden' } \\
\text { - leitava 'der da gefunden } \\
\text { wird' või 'der da kann } \\
\text { gefunden werden' }\end{array}$ & $\begin{array}{l}\text { - leitud 'gefunden' } \\
\text { - leitama 'gefunden } \\
\text { werden' } \\
\text { - leitava 'der, die, das } \\
\text { gefunden wird' }\end{array}$ \\
\hline
\end{tabular}

2 Näitesõnaks on võetud leidma, ehkki sellest sõnast esines näidisparadigma tegelikult ainult Thor Helle grammatikas. Ülejäänud vormid olen moodustanud ise iga autori vormide analoogial. Kui grammatikas on antud eesti vormile saksa või ladina vaste, kajastub see ka siinses tabelis. 


\section{Passiiv ja impersonaal esimestes piiblitõlgetes}

\subsection{Passiiv ja impersonaal Uues Testamendis}

XVII sajandi algul kirja pandud Georg Mülleri jutlustes leidus harva impersonaali (19 korda, nt nente wagkade Lehet nechtaxe) ning sageli saama- ja olema-passiivi: saama + tud-kesksõna 453 ja olema + tud-kesksõna 339 korda (Prillop 2001: 149, 185), näiteks juba esimese jutluse algul kumba piddab kulututh sama ja Iumal olkut kÿtetut ninck tannatuth (Prillop 2001: 149).

Sarnane pilt kestis sajandi lõpukümnenditeni. Nagu keele teoreetilises kirjelduses toimus passiivi- ja impersonaalivormide kasutamiseski otsustav muutus XVII sajandi lõpul: nii grammatikatest kui ka piiblikeelest taandus saama + tud-kesksõna ja sagenesid ühemõtteliselt umbisikulised vormid. Ole$m a+t u d$-kesksõna jäi seevastu grammatikates samale positsioonile ning ka piiblitõlgetes ei kõikunud selle sagedus kuigivõrd. Kuni 1680. aastate keskpaigani kirja pandud Uue Testamendi redaktsioonides leidus üsna tagasihoidlikult umbisikulisi öeldisi (0,2-1,0\% öeldiste koguarvust) ning rohkem saama + tud-kesksõna (3,0-5,2\%). Virginiuste tõlgitud Wastses Testamendis (1686) muutus nende vormide suhe aga vastupidiseks: saama-ühendeid jäi sinna vaid $0,8 \%$, umbisikulisi finiitvorme leidus seevastu $1,9 \%$ ning ulatuslikult hakati kasutama ka varem puudunud $m a$-tegevusnime impersonaali $(1,1 \%){ }^{3}$

Seda murrangut umbisikuliste vormide soosimise ja saama-passiivi tõrjumise suunas ei võetud paaris järgnevas tõlkeversioonis omaks. Alalhoidlikumad kirikuraamatute väljaandjad jäid teatavasti uuendusmeelsete Adrian Virginiuse, Johann Hornungi ja Bengt Gottfried Forseliusega paljuski eriarvamusele, muu hulgas lahknesid nende arusaamad õigekirjast (Põldvee 2010) ja eitusest (Tafenau 2011: 138-139). Seetõttu pole imestada, et XVII sajandi lõpu keelemeeste konservatiivse leeri tõlkeversioonid (Pilistvere käsikiri ja 1693. aastal ilmunud perikoobiraamat) eelistasid varasemale traditsioonile iseloomulikke passiivivorme, uuendusmeelsete käe alt tulnud tekstid (1694. aasta Müncheni käsikiri ja 1695. aastal ilmunud perikoobiraamat) seevastu Wastse Testamendi vormivalikut (vt joonist 1). See vormivalik jäi püsima alates Müncheni käsikirjast, kusjuures saama + tud-kesksõna sagedus oli seal võrreldes Wastse Testamendiga veelgi vähenenud.

\subsection{Passiivi ja impersonaali asümmeetria Uues ja Vanas Testamendis}

Uue Testamendi tõlkeloos väljajoonistuv lihtne, ootuspärane ja kergesti seletatav pilt aga hägustub, kui võtta arvesse ka tollased Vana Testamendi tõlkeversioonid. Nimelt kasutasid samad tõlkijad mõningaid ühendeid Uut ja Vana Testamenti eestindades erinevas mahus (vt joonist 2). Impersonaalsete finiitvormide sagedus jäi kõikjal enam-vähem samaks, kuid ülejäänud tegumoevahendeid oli Uues Testamendis rohkem. Seisundipassiiv olema + tudkesksõna oli Uues Testamendis nähtavalt sagedasem nii Gutslaffi, Virginiuste kui ka täispiibli trükkiviijate tõlkeversioonis. Johannes Gutslaffil oli saa-

3 ma-tegevusnime impersonaal oli enne Wastset Testamenti esinenud vaid Rossihniuse tõlgitud Luuka evangeeliumis ühe korra. Autorite muudest tekstidest pole seda vormi otsitud. 


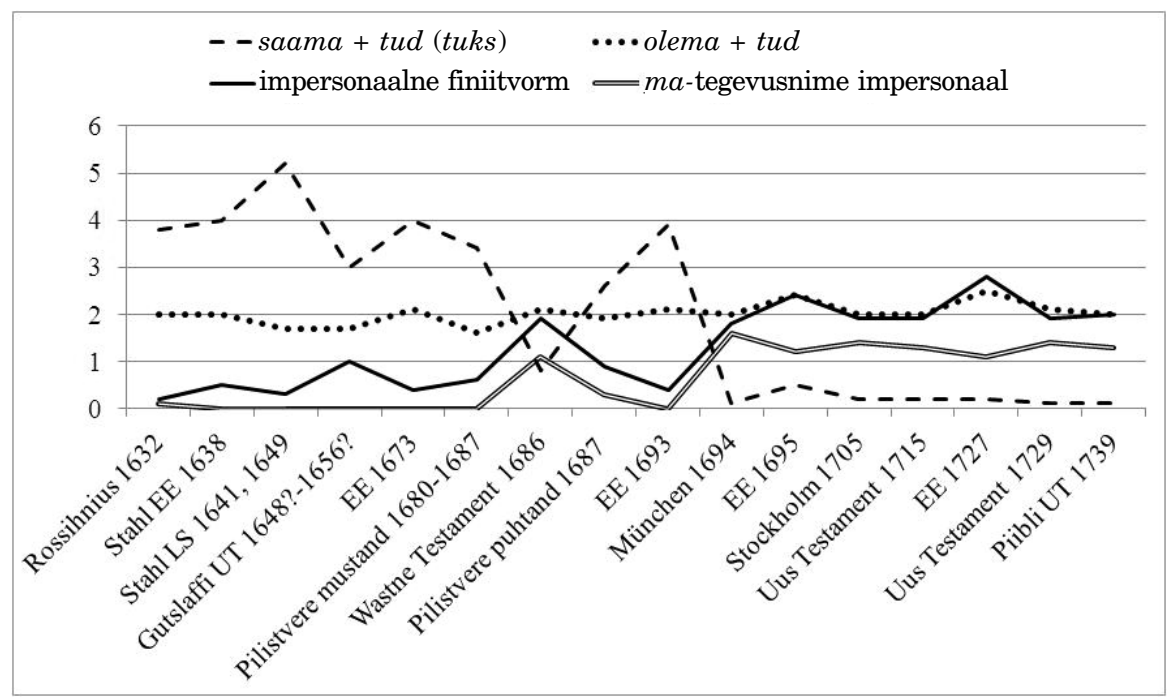

J o o n i s 1. Passiivi- ja impersonaalivormid esimestes Luuka evangeeliumi eestikeelsetes tõlkeversioonides (protsent kõigi öeldiste arvust).

$m a+t u d$ (tuks) Uues Testamendis märksa levinum kui Vanas Testamendis, sama võib täheldada Virginiuste puhul, kes seda ühendit küll tunduvalt vähem tarvitasid. Virginiusi ja täispiibli väljaandjaid omakorda ühendab see, et nad kasutasid $m a$-tegevusnime impersonaali Uues Testamendis palju tihedamini kui Vanas Testamendis.

- Gutslaffi UT 1648?-1656?

$\square$ Gutslaffi VT 1648?-1656?

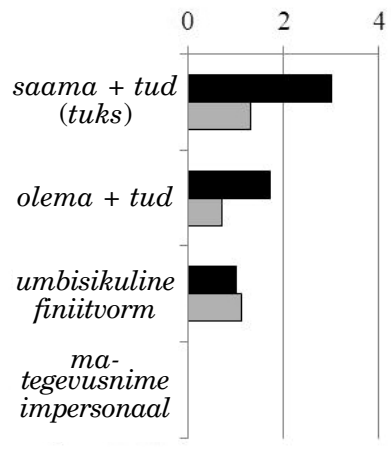

- Wastne Testament 1686

$\square$ Virginiuste VT 1687-1690

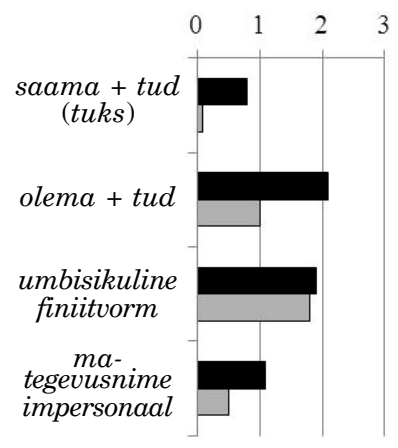

- Piibli UT 1739

口 Piibli VT 1739

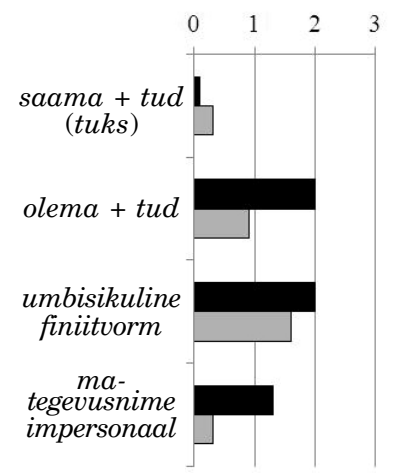

J o o n is 2. Passiivi- ja impersonaalivormide sagedus samade autorite Uue ja Vana Testamendi keeles (protsent kõigi öeldiste arvust).

Nende vormide sageduserinevuse põhjusi võib olla mitu, näiteks piibliosade erinev algkeel, tekstide erinev sisu või nende eestindamiskäigu erinevus. Praeguses artiklis jätan kõrvale esimesed kaks võimalikku põhjendust, sest siinsed andmed ei ole nende paikapidavuse uurimiseks piisavad. Kolmas põhjendus tundub aga sobivat küll. 
Impersonaalsete ja passiivsete keelendite kasutamises tundub tõepoolest peegelduvat piibliosade erinev tõlkelugu: see, et Uue Testamendi versioonid toetusid suuremal või vähemal määral eelnevale, Vana Testamendi versioonid olid aga iseseisvad tõlked (vähemalt praeguse uurimisseisu kohaselt). Uues Testamendis kasutasid tõepoolest enamasti mitu järjestikust tõlget sama vormi ja mõnikord püsis sõnastus muutumatuna lausa kõikides redaktsioonides 1630 . aastatest kuni 1720 . aastateni.

Uue Testamendi passiivi või impersonaali sisaldanud kohtadest moodustavad tervelt $48 \%$ sellised, kus verbivorm püsis terve sajandi muutumatuna (vt joonist 3). Ka Vana Testamendi kolme versiooni passiivi- või impersonaalivorm langes kokku üllatavalt tihti, 29 protsendil juhtudest, seejuures leidus nii UT-s kui ka VT-s ühepalju eelkäijatega kokkulangevaid umbisikulisi vorme, nimelt $12 \%$. Algusest lõpuni püsima jäänud passiiviühendeid oli Uues Testamendis aga märgatavalt enam: saama + tud-kesksõna UT-s $15 \%$ ja VT-s $8 \%$ ning olema + tud-kesksõna UT-s $21 \%$ ja VT-s $9 \%$; $m a$-tegevusnime impersonaal on neis rehkendustes arvestatud kokku saama-passiiviga, sest just viimase asendajana võeti see kasutusele 75 juhul 77-st.

Nagu jooniseltki näha, on Uues Testamendis tõepoolest rohkem kohti, kus püsib olema-passiiv või algul saama-passiiv ja hiljem seda asendav ma-tegevusnime impersonaal.

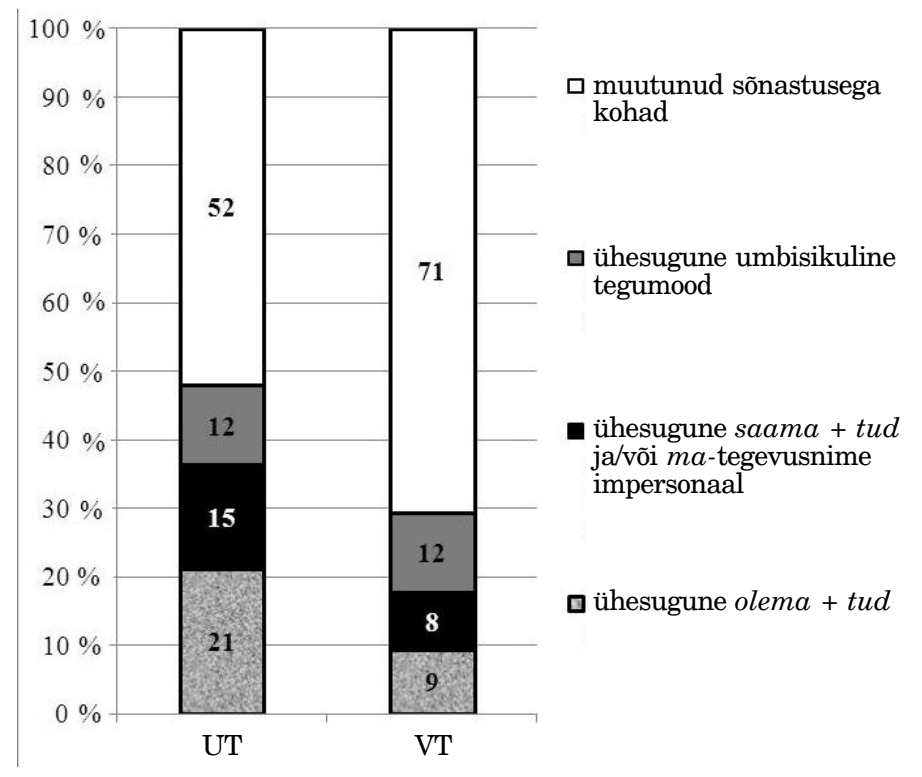

J o o n is 3. Ühesugusena 4 püsinud passiivi- ja impersonaalivormide osatähtsus Uue ja Vana Testamendi versioonides (protsent kõigist passiivi või/ja impersonaali sisaldanud kohtadest).

4 Uue Testamendi puhul on siia hulka arvestatud ka juhtumid, kus muidu stabiilsest tavast erines 1-2 versiooni. 


\section{4. Üksikkeelendite kasutamise dünaamika}

\section{1. saama + tud-kesksõna}

Passiivsete ja impersonaalsete keelendite seas oli XVII sajandil selgelt kõige populaarsem saama + tud-kesksõna. Seda tarvitati ohtralt sajandi algul Mülleri jutlustes ning järgnenud UT tõlgetes kuni sajandi lõpukümnenditeni (3,0-5,2 \% öeldistest). Muutuse tõi Virginiuste tõlgitud Wastne Testament, mis kasutas saama-passiivi varasemast märksa vähem $(0,7 \%)$. Sellele vahetult järgnenud tõlkeversioonides, mis lähtusid alalhoidlikumast keeleideaalist, oli saama-passiiv endiselt levinud. Ühendist loobumine kinnistus alates Müncheni käsikirjast, kuhu jäi vaid kolm saama + tud-kesksõna $(0,1 \%)$. Selle asemele tuli enamasti mõni umbisikuline vorm. VT tõlgetes esines saama-passiivi vähe aga juba XVII sajandil: Gutslaffil 1,3\% ja Virginiustel 0,1\%. Algusest lõpuni püsis saama-passiiv ainult meieisapalve sõnastuses, vt Lk 11:2:

Gutslaff ?1648-?1656: T.laus neihnde w. Kun teije tahhate palwelda; sihs üttelket: Issa meije Ken s. ollet Taiwa sissen, pöhatut sahko su Nimme, Su rick tulcko, su Tachtminne sündko, Kui Taiwa sissen (ninda) ka mah pähl.

Piibli UT 1739: Agga temma ütles neile: Kui teie loete, siis üttelge: Meie Issa, kes sa olled taewas: pühhitsetud sago sinno nimmi: sinno kunningriik tulgo: sinno tahtminne sündko, kui taewas, nenda ka Ma peäl:

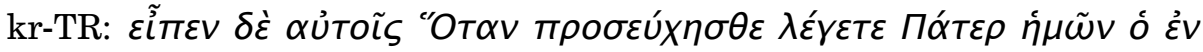

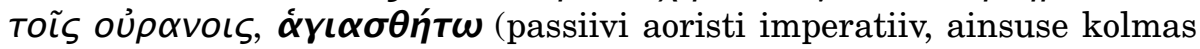

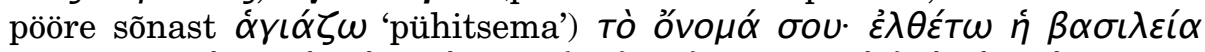

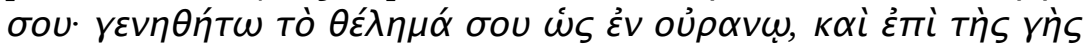

ld-V: et ait illis cum oratis dicite Pater sanctificetur (passiivi konjunktiiv, ainsuse kolmas pööre sõnast sanctifico 'pühitsema') nomen tuum adveniat regnum tuum

sks-L: Und er sprach zu ihnen: Wenn ihr betet, so sprecht: Unser Vater im Himmel, dein Name werde geheiligt (I konjunktiiv, ainsuse kolmas pööre sõnast werden 'saama' ja II partitsiip sõnast heiligen 'pühitsema'). Dein Reich komme. Dein Wille geschehe auf Erden wie im Himmel

UT-s tõlgiti saama-ühenditega kohti, kus Lutheril seisis enamasti 'werden + II partitsiip' ning kr-TR-s ja ld-V-s sünteetiline passiiv, kusjuures kõige sagedasem oli paralleel Lutheri werden-passiiviga. VT saama-ühendite kõige sagedasem paralleel oli aga hoopis mõni heebrea passiivitüvi (enamasti nifal ${ }^{5}{ }^{5}$ Kõige järsemalt eristuvadki selle näitaja poolest Gutslaffi Vana ja Uue Testamendi tõlge: VT saama-passiividest vaid $54 \%$ langes kokku Lutheri werden-passiividega, UT tõlkes leidus niisuguseid kokkulangevusi aga märksa rohkem (80\%) nagu teisteski XVII sajandi UT tõlkeversioonides.

5 Gutslaffi VT saama + tud-kesksõna 48 esinemisjuhu paralleeliks oli 32 korral nifal, neljal hof'al ja üks kord pu'al. Virginiuste VT kolme esinemisjuhu paralleeliks oli kahel korral nif'al, ühel hitpa'el. Täispiibli 11 esinemisjuhu paralleeliks oli üheksal korral nif'al, kahel pu'al. 
Gutslaffi UT ja VT eristusid ka selle poolest, et Luuka evangeeliumis kasutas ta $t u d$-kesksõna kõrval mõnikord selle translatiivset vormi ${ }^{6}$ (15 korda ehk $15 \%$ kõigist tema saama-passiividest, nt saihit Kastatuts 'nad ristiti'), Esimeses Moosese raamatus seevastu ainult ühel korral. Translatiivne konstruktsioon muutub tal üldisemaks alates Teisest Moosese raamatust (Ross 2009: 17). Virginiused kasutasid oma lõunaeestikeelses UT-s saama-passiivi lausa valdavalt tuks-lõpulisena (27 korda, 96 \%; nende põhjaeestikeelses VT-s on saama-passiiv tud-lõpuline). Ehkki mõlemas lõunaeestikeelses UT tõlkes leidub tuks-juhtumeid, tulevad need üksnes kahel korral ette samas salmis, seega ei saa öelda, et Virginiused oleks Gutslaffi kopeerinud, vaid et mõlemas tõlkes oli tegu produktiivse malliga. ${ }^{7}$

\section{2. olema + tud-kesksõna}

Kõige stabiilsemana püsis tollases kirjakeeles seisundipassiiv, mida kasutati enam-vähem samal määral terve täispiibli tõlkeloo vältel ning mida oli esinenud üsna palju juba Mülleri jutlustes. Seejuures leidus olema-passiivi nagu saama-passiivigi UT-s märksa rohkem kui VT-s: olema + tud-kesksõna sagedus UT-s jäi vahemikku 1,6-2,5 \% kõigist öeldistest, VT-s 0,7-1,0\%. Nii UT-s kui ka VT-s leidus võrreldes ülejäänud passiivsete ja impersonaalsete keelenditega lausa üsna palju selliseidki kohti, kus olema-passiiv esines kõigis tõlkeversioonides, nt $1 \mathrm{Ms}$ 10:5:

Gutslaffi VT 1648?-1656?: Neistsinnatzist ommat weljalaotut neihde pagganite sahret noihde maihde sissen, ütz iggalick omma keele perra, neihde sugkuwössade perra, neihde rahgwa sean

Virginiuste VT 1687-1690: Neist oñat wäljalahotut Pagganatte Maa, nink Sarede sisse, iggaüks oma kele perra, omas suggus nink Rahwas

Piibli VT 1739: Neist on jaetud pagganatte sared nende made sees, igga üks omma kele järrele, nende sugguwössade järrele nende rahwa seas

hbr: mèēlleh nifarad $\underline{\text { u }}$ (nif'al-tüvi, perfekt sõnast pârad 'jagama') îyê hagwōyim ba'arașōtāam 'îš lilašōnwō lamišapahōtāam baḡwōyēhem

ld-V: ab his divisae sunt (passiivi perfekti partitsiip sõnast divido 'jagama' ja mitmuse kolmas pööre sõnast sum 'olema') insulae gentium in regionibus suis unusquisque secundum linguam et familias in nationibus suis

sks-L: Von diesen sind ausgebreitet (mitmuse kolmas pööre sõnast sein 'olema' ja II partitsiip sõnast ausbreiten 'levima') die Inseln der Heiden in ihren Ländern, jegliche nach ihren Sprachen, Geschlechtern und Leuten

${ }^{6}$ Vorm esineb Gutslaffil tuts- ja Virginiustel tus-lõpuga.

7 Hella Keem kirjutab Gutslaffi grammatika ülevaates, et ehkki autori rohked saamapassiivi vormid pole lõunaeesti rahvakeelele omased, on murdepärane tema kasutatud translatiivne konstruktsioon saama + tuks: „Lausa nõutuks teeb see Gutslaffi passiiv. Indikatiiv algab taas saama-verbi vormide uputusega, millel Lõuna Eesti murretes pole alus.... Ainuke koht, kuhu see sâb ja saì sobib, on Tartu ja Võru murde translatiivsed eri varjundiga lausekonstruktsioonid, mis näitavad mingi tegevuse täielikku lõpetatust” (Keem 1998: 330-331). 
Enamasti kasutati olema + tud-kesksõna seal, kus ka Lutheri tõlkes oli samalaadne vorm, nimelt sein + II partitsiip. Eri tõlkeversioonides jäi olema $+t u d$-kesksõna ja Lutheri sein-passiivi kattuvus 65-85 \% vahele. VT puhul oli kõrge kattuvus ka heebrea passiivsete vormidega (74-79\%), eriti pa'al'i passiivi partitsiibiga. ${ }^{8}$ Vähem oli paralleele Vulgata passiivi 'olema'-abiverbiliste liitvormidega (42-67 \%) ning UT tõlgetel kreeka passiiviga (35-47 \%).

\section{3. ma-tegevusnime impersonaal}

$m a$-tegevusnime impersonaali hakati rohkesti tarvitama XVII sajandi lõpul Wastses Testamendis, varem oli leidunud vaid üks selline vorm Rossihniuse Luuka evangeeliumis. Hornungi ja Thor Helle grammatikates oli selle vormi impersonaali saksa vasteks pandud werden + II partitsiip ning piiblitõlgetes asendatigi sellega peaaegu alati varasemat saama-passiivi. Seetõttu pole imestada, et enamikku UT $m a$-tegevusnime impersonaali vormidest kasutati seal, kus Lutheril oli werden + II partitsiip. UT ma-tegevusnime impersonaalil oligi kõige suurem kattuvus sks-L-i werden-passiiviga, jäädes eri tõlkeversioonides 81-89 \% vahele. Pisut väiksem oli kattuvus ld-V passiiviga (70-76 $\%)$ ja kr-TR passiiviga (61-65\%).

VT tõlgetes leidus $m a$-tegevusnime impersonaali harvem ning kuigi sageli see sks-L-i werden-passiiviga samas kohas ei olnud, sagedasim paralleel oli hoopis heebrea passiiv, enamasti nifal-tüvi (Virginiustel $83 \%$, täispiiblis $100 \%) .{ }^{9}$ UT-s oli $m a$-tegevusnime impersonaal mõeldud asendama varasema traditsiooni saksamõjulist saama-passiivi, VT-s polnud niisugust asendust tarvis.

Enamasti väljendati $m a$-tegevusnime impersonaali ühenditega tulevikku, kusjuures Wastses Testamendis esinesid tuleviku abiverbidena nii saama kui ka pidama, alates Müncheni käsikirjast ainult pidama, vt nt Lk 14:14:

Wastne Testament: 1686: Sis ollet sinna önnis: Sest neil ei olle mitte sulle tassoda: Sest sinnole sahb massetama Öigide Üllestössemissen

München 1694: Siis olled sinna önnis: sest neil ei olle middakid sulle se wasto anda; sest sulle peab tassutama Öigede üllestousmissel

(vrd Pilistvere mustand 1680-1687: Sih $\beta$ ollet Sinna önnis, sest nemmat woiwat Sul sedda mitte taßuma, sedda saht Sul taßatut sahma, nende oikedade üllestaußmißest)

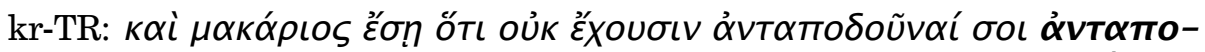

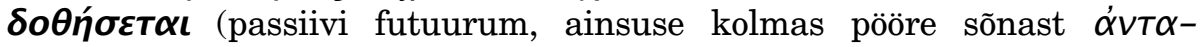

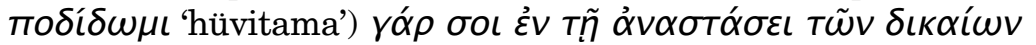

8 Gutslaffi VT olema + tud-kesksõna 26 esinemisjuhu paralleeliks oli kümnel korral pa'al'i passiivi partitsiip, kuuel nif'al, neljal pu'al. Virginiuste VT 32 esinemisjuhu paralleeliks oli 12 korral pa'al'i passiivi partitsiip, kuuel nif'al, neljal pu'al, kahel huf'al. Täispiibli 31 esinemisjuhu paralleeliks oli 12 korral pa'al'i passiivi partitsiip, üheksal nif'al, kolmel pu'al ja üks kord huf'al.

9 Virginiuste VT ma-tegevusnime impersonaali 18 esinemusjuhu paralleeliks oli 13 korral nif'al ning üks kord $h u f^{\prime} a l$ ja hitpa'el. Täispiibli $12 m a$-tegevusnime impersonaali paralleeliks oli kümnel korral nif'al ja kahel juhul huf'al. 
ld-V: et beatus eris quia non habent retribuere tibi retribuetur (passiivi futuurum, ainsuse kolmas pööre sõnast retribuo 'tagastama') enim tibi in resurrectione iustorum

sks-L: so bist du selig; denn sie haben's dir nicht zu vergelten, es wird (ainsuse kolmas pööre sõnast werden 'saama') dir aber vergolten werden (II partitsiip sõnast vergelten 'tasuma' ja infinitiiv sõnast werden 'saama') in der Auferstehung der Gerechten

\subsection{Umbisikulised finiitvormid}

Impersonaal polnud XVII sajandi lõpuni kirikukeeles kuigi levinud: enne Wastset Testamenti moodustasid umbisikulised finiitvormid UT tõlgetes vaid 0,2-1,0 \% öeldistest, sealt alates 1,8-2,8 \%. Paaris Wastsele Testamendile vahetult järgnenud konservatiivses tõlkeversioonis kasutati impersonaali taas harva ning kunagisest märksa umbisikulisem keeletarvitus jäi püsima alates Müncheni käsikirjast. Vana Testamendi puhul sellist murrangut ei toimunud, seda kasutati kõigis kolmes VT tõlkes üsna ühepalju (1,1-1,8 \%).

Finiitne impersonaal erines UT-s tugevalt saama-ja olema-passiivist ning $m a$-tegevusnime impersonaalist, sest viimastega tõlgiti enamjaolt selliseid kohti, kus sks-L oli kasutanud mõnd konkreetset passiivset keelendit. UT finiitsed impersonaalivormid seevastu haakusid kõige paremini ld-V sõnastusega: 65-100\% UT eri tõlgete impersonaalidest paiknes samas kohas, kus ld-V passiivivorm, ja 42-47 \% VT impersonaalidest seal, kus ladina 'olema' + partitsiip. Ühegi saksa ega kreeka vormiga polnud nii suurt kattuvust. ${ }^{10}$ Kõik kolm VT tõlget kasutasid impersonaalivorme kõige sagedamini seal, kus heebrea keeles oli passiivitüvi, enamasti nif al11 (62-74 \% kõigist VT tõlkeversiooni finiitsetest impersonaalivormidest), sks-L-i ja ld-V keelenditega oli kattuvus väiksem. Vt nt $1 \mathrm{Ms} 2: 10$ :

Gutslaffi VT 1648?-1656?: Ninck ütz jögge tulli welja sest armsambast mahst sedda ajda kastma, ninck lahhutati sählt, ninck saih nellas harras

(vrd Piibli VT 1739: Ja jöggi läks wälja Edenist sedda rohho-aeda kastma, ja ta lahkus seält ja sai neljaks arruks).

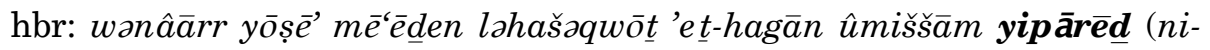
$f^{\prime} a l$-tüvi, imperfekt sõnast pârad 'jagama') wahāyâ la'arabā'â rā'šìm

ld-V: et fluvius egrediebatur de loco voluptatis ad inrigandum paradisum qui inde dividitur (passiivi ainsuse kolmas pööre sõnast divido 'jagama') in quattuor capita

10 Erandiks oli Johannes Gutslaffi Uue Testamendi tõlge, milles esines rohkem paralleele kr-TR-i ja sks-L-i sõnastusega kui ld-V omaga.

11 Gutslaffi VT impersonaali finiitvormi 41 esinemusjuhu paralleeliks oli 18 korral nif'al, neljal huf'al, kolmel pa'al'i passiivi partitsiip, kahel pu'al. Virginiuste VT 60 vormi paralleeliks oli 29 korral nif'al, kolmel huf'al, kolmel pu'al, kahel pa'al'i passiivi partitsiip. Täispiibli 62 vormi paralleeliks oli 33 korral nif'al, seitsmel huf'al, neljal pa'al'i passiivi partitsiip ja üks kord pu'al. 
sks-L: Und es ging aus von Eden ein Strom, zu wässern den Garten, und er teilte (preteeritumi ainsuse kolmas pööre sõnast teilen 'jagama') sich von da in vier Hauptwasser

Impersonaaliga seoses pakub huvi veel vanemast kirikukeelest registreeritud impersonaali ja passiivi piirimaile jääv kset-tunnuseline mitmuse kolmanda pöörde vorm. Wanradti-Koelli katekismuses leidub vorm kuthsutaxet 'kutsutakse' (kuthsutaxet nema) ning Georg Mülleri 36. jutluses kolm korda

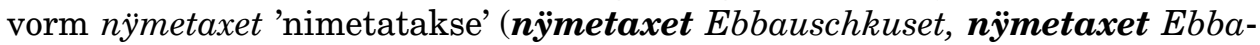
uschckuset ja n̈̈metaxet Pattuset). Vormi lõpus olevat $t$-d võib pidada mitmuse tunnuseks ning vormi tervikuna pöörduvaks passiiviks, mida esineb soome vanas kirjakeeles ja lõunaeesti murretes. Veel kolmel juhul, kus tegevusobjekt on mitmuses, piirdus Müller siiski kse-tunnuselise vormiga (leutaxe paliu heütüth Inimeßet, nente wagkade Lehet nechtaxe, Neet kolmet sarnatzet Suggudt Leutaxe) (Prillop 2001: 96-97). Hilisemas piiblikeeles, vähemasti vaadeldud korpuses, $k s e t$-lõpulist vormi enam ette ei tule.

\section{Kokkuvõtteks}

Piibliosade erinev tõlkelugu mõjutas ka passiivi ja impersonaali kasutamist. Pikema traditsiooniga UT oli passiivitarvituses alalhoidlikum ning Lutherilähedasem. Kõigi UT tõlgete saama-passiivide ja ma-infinitiivi impersonaali kohal seisis Lutherilgi enamasti 'saama' + kesksõna ning olema + tud-kesksõna kohal 'olema' + kesksõna. Ühegi kreeka ega ladina passiivse keelendiga nii sagedast paralleeli ei tekkinud. Selline Lutheri-lähedus iseloomustas neidki tõlkeversioone, mida peetakse otse kreeka originaalist tõlgituks.

Teisiti oli umbisikuliste finiitvormidega, mille kasutamine haakus Lutheri passiivi ja impersonaaliga märksa harvem. Hoopis sagedasemaks osutus paralleel ladina Vulgata passiiviga, mis võib olla tingitud sellest, et teatavad väljendid olid kinnistunud juba katoliku ajal (nt impersonaal kutsutakse seal, kus ladina keeles on passiiv vocatur ja saksa keeles aktiiv hei $\beta t$ ). Kuni XVII sajandi lõpuni esines piiblitõlgetes umbisikulist tegumoodi siiski väga vähe. Sel ajal lisandunud rohkete impersonaalivormide põhjuseks võib pidada soovi kaugeneda saksapärasest sõnastusest, mistõttu pole imestada, et suurt osa uutest impersonaalidest ei kasutatud Lutheriga sarnaselt. Saksapärasusest kaugeneti ka varem populaarsest saama-passiivist loobumisega: sellest jäid pärast XVII sajandi lõpu keelereformi piiblitõlgetesse vaid üksikud, näiteks meieisapalve pühitsetud saagu sinu nimi.

Võrreldes UT tõlgetega, kus toimus XVII sajandi lõpus saama-passiivist loobuv ja umbisikulisi vorme ausse tõstev murrang, leidus kõigis kolmes VT versioonis vähem passiivi ja impersonaali kui samade tõlkijate UT-s. Erinevalt UT-st polnud kõige sagedasem eesti keelendite paralleel mitte Lutheri saksa tõlkega ega ladina Vulgataga, vaid hoopis heebrea Tanahiga. VT tõlkijad kasutasid eesti passiivi- ja impersonaalivorme (eriti impersonaalseid finiitvorme ja $m a$-tegevusnime impersonaali ühendeid) tihti seal, kus heebrea keeleski oli passiivitüvi. Enamasti oli seejuures tegemist lihtsa passiivi nif'al'iga, lisaks esinesid kausatiivne passiiv $h u f^{\prime} a l$, intensiivne passiiv $p u^{\prime} a l$, intensiivne refleksiiv hitpa'el ja pa'al'i passiivne partitsiip. Lutheriga oli 
paralleel sagedasem ainult olema + tud-kesksõna ja Virginiuste saama + tudkesksõna puhul.

Praeguses uurimisseisus on raske öelda, kuivõrd on samade tõlkijate erinev keel UT-s ja VT-s tingitud piibliosade erinevast originaalkeelest ja sisust. Küll aga tundub erinevus kinnitavat seda, et UT puhul on rohkem toetutud pikaaegsele Lutheri-eeskujulisele passiivi kasutamise traditsioonile (ka siis, kui sellest distantseeruda püüti), VT puhul aga mitte. Ootuspärane on seegi, et XVII sajandi lõpus rakendasid uut, saksalikust sõnastusest kaugenevat vormivalikut tolleaegsed keelereformaatorid ja seda eirasid konservatiivid. Esmakordselt Wastses Testamendis ilmnenud vormieelistused jäid UT traditsioonis püsima alates Müncheni käsikirjast.

Artikkel on valminud ETF-i grandi nr 7896 ja sihtfinantseeritava projekti SF0050037s10 toel.

Lis a.

Keelendite arv ja osakaal vaadeldud piibliversioonides ${ }^{12}$

\begin{tabular}{|l|c|c|c|c|c|}
\hline Lühend & $\begin{array}{c}\text { Umb- } \\
\text { isikuline }\end{array}$ & $\begin{array}{c}\text { saama }+ \\
\text { tud (tuks) }\end{array}$ & $\begin{array}{c}\text { ma-infinitiivi } \\
\text { impersonaal }\end{array}$ & $\begin{array}{c}\text { olema + } \\
\text { tud }\end{array}$ & $\begin{array}{c}\text { Öeldisi } \\
\text { kokku }\end{array}$ \\
\hline Rossihnius 1632 & $3(0,2 \%)$ & $49(3,8 \%)$ & $1(0,1 \%)$ & $26(2,0 \%)$ & 1302 \\
\hline Stahl EE 1638 & $5(0,5 \%)$ & $41(4,0 \%)$ & & $20(2,0 \%)$ & 1016 \\
\hline Stahl LS 1641, 1649 & $2(0,3 \%)$ & $30(5,2 \%)$ & & $10(1,7 \%)$ & 580 \\
\hline $\begin{array}{l}\text { Gutslaffi UT } \\
\text { 1648?-1656? }\end{array}$ & $33(1,0 \%)$ & $100(3,0 \%)$ & & $57(1,7 \%)$ & 3322 \\
\hline $\begin{array}{l}\text { Gutslaffi VT } \\
1648 ?-1656 ?\end{array}$ & $41(1,1 \%)$ & $48(1,3 \%)$ & & $27(0,7 \%)$ & 3687 \\
\hline $\begin{array}{l}\text { EE 1673 } \\
\text { Pilistvere mustand } \\
1680-1687\end{array}$ & $21(0,6 \%)$ & $110(3,4 \%)$ & & $23(2,1 \%)$ & 1115 \\
\hline $\begin{array}{l}\text { Wastne Testament } \\
1686\end{array}$ & $79(1,9 \%)$ & $32(0,8 \%)$ & $48(1,1 \%)$ & $88(2,1 \%)$ & 4233 \\
\hline $\begin{array}{l}\text { Virginiuste VT } \\
\text { 1687-1690 }\end{array}$ & $60(1,8 \%)$ & $3(0,1 \%)$ & $17(0,5 \%)$ & $33(1,0 \%)$ & 3283 \\
\hline $\begin{array}{l}\text { Pilistvere puhtand } \\
1687\end{array}$ & $28(0,9 \%)$ & $85(2,6 \%)$ & $9(0,3 \%)$ & $63(1,9 \%)$ & 3233 \\
\hline EE 1693 & $5(0,4 \%)$ & $43(3,9 \%)$ & & $23(2,1 \%)$ & 1114 \\
\hline München 1694 & $75(1,8 \%)$ & $3(0,1 \%)$ & $67(1,6 \%)$ & $84(2,0 \%)$ & 4242 \\
\hline
\end{tabular}

12 Tabelis olev absoluutarv näitab, mitu korda keelend tõlkeversioonis esines. Protsent näitab, kui suur oli selle keelendi osatähtsus kõigist tõlkeversiooni öeldistest. UT korpusse kuuluvad kõik vastavas tõlkeversioonis olemasolevad Luuka evangeeliumi read, VT korpusse 1 . Moosese raamatu 1.-35. peatüki kõik olemasolevad read. 


\begin{tabular}{|l|c|c|c|c|c|}
\hline Lühend & $\begin{array}{c}\text { Umb- } \\
\text { isikuline }\end{array}$ & $\begin{array}{c}\text { saama } \\
\text { tud }(\text { tuks })\end{array}$ & $\begin{array}{c}\text { ma-infinitiivi } \\
\text { impersonaal }\end{array}$ & $\begin{array}{c}\text { olema }+ \\
\text { tud }\end{array}$ & $\begin{array}{c}\text { Oeldisi } \\
\text { kokku }\end{array}$ \\
\hline EE 1695 & $26(2,4 \%)$ & $6(0,5 \%)$ & $13(1,2 \%)$ & $26(2,4 \%)$ & 1092 \\
\hline Stockholm 1705 & $79(1,9 \%)$ & $8(0,2 \%)$ & $61(1,4 \%)$ & $86(2,0 \%)$ & 4266 \\
\hline Uus Testament 1715 & $81(1,9 \%)$ & $9(0,2 \%)$ & $56(1,3 \%)$ & $86(2,0 \%)$ & 4285 \\
\hline EE 1727 & $31(2,8 \%)$ & $2(0,2 \%)$ & $12(1,1 \%)$ & $28(2,5 \%)$ & 1110 \\
\hline Uus Testament 1729 & $84(1,9 \%)$ & $6(0,1 \%)$ & $60(1,4 \%)$ & $90(2,1 \%)$ & 4332 \\
\hline Piibli VT 1739 & $60(1,6 \%)$ & $11(0,3 \%)$ & $11(0,3 \%)$ & $32(0,9 \%)$ & 3712 \\
\hline Piibli UT 1739 & $86(2,0 \%)$ & $6(0,1 \%)$ & $58(1,3 \%)$ & $87(2,0 \%)$ & 4328 \\
\hline
\end{tabular}

\section{Allikad}

\section{A. Käsikirjalised}

EPAK = Eesti piiblitõlke ajalooline konkordants. $h t t p: / / w w w . e k i . e e / p i i b e l$.

Gutslaffi UT 1648?-1656? = Johannes Gutslaffi lõunaeestikeelne Uue Testamendi tõlkekäsikiri, mis on säilinud Heinrich Gösekeni ümberkirjutusena (kasutatud EPAK-i jaoks sisestatud varianti).

Gutslaffi VT 1648?-1656? = Johannes Gutslaffi lõunaeestikeelne Vana Testamendi tõlkekäsikiri (EPAK).

München 1694 = Arvatavasti ümberkirjutus Johann Hornungi tõlkeversioonist, mille ta koostas 1687.-1688. aastal vahetult pärast Pilistvere piiblikonverentsi. - Põhjaeestikeelsed Uue Testamendi tõlked 1680-1705. Luuka evangeelium. Apostlite teod. Koost K. Ross, toim H. Reila, K. Ross, K. Tafenau. Tallinn: Eesti Keele Sihtasutus, 2007, lk 11-235 (EPAK).

Pilistvere mustand 1680-1687 = Uue Testamendi tõlkekäsikirjad, mille kallal töötati 1687. aastal Pilistvere piiblikonverentsil. - Põhjaeestikeelsed Uue Testamendi tõlked 1680-1705. Luuka evangeelium. Apostlite teod. Koost K. Ross, toim H. Reila, K. Ross, K. Tafenau. Tallinn: Eesti Keele Sihtasutus, 2007, lk 10-180 (EPAK).

Pilistvere puhtand 1687 = Pilistvere piiblikonverentsil toimetatud käsikirja lõplik kuju. - Põhjaeestikeelsed Uue Testamendi tõlked 1680-1705. Luuka evangeelium. Apostlite teod. Koost K. Ross, toim H. Reila, K. Ross, K. Tafenau. Tallinn: Eesti Keele Sihtasutus, 2007, lk 10-179 (EPAK).

Stockholm 1705 = Käsikiri, mis valmis Põhjasõja ajal Tallinnas Hornungi tõlkeversiooni üheskoos toimetades. - Põhjaeestikeelsed Uue Testamendi tõlked 1680-1705. Luuka evangeelium. Apostlite teod. Koost K. Ross, toim H. Reila, K. Ross, K. Tafenau. Tallinn: Eesti Keele Sihtasutus, 2007, lk 11-235 (EPAK). Virginiuste VT 1687-1690 = Andreas ja Adrian Virginiuse tõlgitud põhjaeestikeelne Vana Testamendi käsikiri (EPAK). 


\section{B. Trükitud}

EE 1673 = Di gewöhnliche Evangelia und Episteln. Reval: Adolph Simon.

EE 1693 = Nehd pöhat Evangeliumit nink Epistlit keike Ahsta lebbi, Mah Kehle sehs kirjotut, Tal-Linnas: Christoff Brendeken.

EE 1695 = Ewangeliumme ning Epistli-Loud. Riga: Johann Georg Wilcken.

EE 1727 = Keik Ewangeliummid ning Epistlid keige se Aasta läbbi. Tallinn: Joan Köler.

Piibli UT 1739 = Piibli Ramat. Tallinn: Jakob Joan Köler, 1739 [Faksiimileväljaanne: Piibliraamat. Tallinn: Eesti Raamat, 1990] (EPAK).

Piibli VT 1739 = Piibli Ramat. Tallinn: Jakob Joan Köler [Faksiimileväljaanne: Piibliraamat. Tallinn: Eesti Raamat, 1990] (EPAK).

Rossihnius 1632 = Joachim Rossihnius, Evangelia und Episteln auff alle Sontage durchs gantze Jahr. Riga: Gerhard Schröder, 1632 (EPAK).

Stahl EE 1638 = Heinrich Stahl, Hand- und Hauszbuch Für die Pfarherren und Hausz-Väter Esthnischen Fürstenthumbs. Dritter Theil. Revall: Christoff Reusner (EPAK).

Stahl LS 1641 = Heinrich Stahl, Leyen Spiegel. Winter Theil. Reval: Heinrich Westphal 1641 (Vana kirjakeele korpus. http://www.murre.ut.ee/vakkur/ Korpused/korpused.htm).

Stahl LS 1649 = Heinrich Stahl, Leyen Spiegel. Sommer-Theil. Reval: Heinrich Westphal, 1649 (Vana kirjakeele korpus. http://www.murre.ut.ee/vakkur/ Korpused/korpused.htm).

Uus Testament 1715 = Meie Issanda Jesusse Kristusse Uus Testament Ehk Jummala Ue Sädusse Sanna. Tallinn: Johan Kristow Prendeken, 1715 [Faksiimileväljaanne: Uus Testament 1715. Tallinn: Eesti Rahvusraamatukogu, 2004.] (Vana kirjakeele korpus. http://www.murre.ut.ee/vakkur/Korpused/korpused. htm).

Uus Testament 1729 = Meie Issanda JESUSSE KRISTUSSE uus Testament ehk Ue Seädusse Ramat. Tallinn: Joan Köler.

Wastne Testament 1686 = Meie Jssanda Jesusse Kristusse Wastne Testament. Riga: Johann Georg Wilcken,1686 [Faksiimileväljaanne: Wastne Testament 1686. Tallinn: Eesti Keele Sihtasutus, 2001] (EPAK).

\section{Kirjandus}

Brettle r, Marc Zvi 2002. Biblical Hebrew for Students of Modern Israeli Hebrew. New Haven-London: Yale University Press.

D uff, Jeremy 2009. The Elements of New Testament Greek. Cambridge: Cambridge University Press.

Ere lt, Mati, Ka si k, Reet, M et s l a ng, Helle, R a j a n di, Henno, R o s s, Kristiina, S a a ri, Henn, Ta e l, Kaja, Var e, Silvi 1993. Eesti keele grammatika II. Süntaks. Lisa: kiri. Tallinn: Eesti Teaduste Akadeemia Eesti Keele Instituut.

Erelt, Mati, Erelt, Tiiu, R os s, Kristiina 2007. Eesti keele käsiraamat. Kolmas, täiendatud trükk. Tallinn: Eesti Keele Sihtasutus.

Gutslaff 1648 [1998] = Johannes Gutslaff, Observationes Grammaticae circa linguam Esthonicam. Grammatilisi vaatlusi eesti keelest. Toim Marju Lepajõe, 
Jaak Peebo. (Tartu Ülikooli eesti keele õppetooli toimetised 10.) Tartu: Tartu Ülikool, 1998.

Gös e k e n, Heinrich 1660. Manuductio ad Linguam Oesthonicam, Anführung zur Öhstnischen Sprache, Bestehend nicht alleine in etlichen praeceptis und observationibus, Sondern auch In Verdolmetschung vieler Teutschen Wörter. Reval: Adolph Simon.

Hel b i g, Gerhard, Ke m p te r, Fritz 1997. Das Passiv. Leipzig: Langenscheidt.

H o b e r g, Rudolf, H o b e r g, Ursula 1997. Der kleine Duden. Deutsche Grammatik: eine Sprachlehre für Beruf, Fortbildung und Alltag. Tallinn: TEA Kirjastus.

H o r n u n g, Johann [1693]. Grammatica Esthonica, brevi, Perspicua tamen methodo ad Dialectum Revaliensem. Riga: Literis Joh. Georg Wilck.

K e e m, Hella 1998. Johannes Gutslaffi grammatika eesti keel ja Urvaste murrak. - Observationes Grammaticae circa linguam Esthonicam. Grammatilisi vaatlusi eesti keelest. Toim Marju Lepajõe, Jaak Peebo. (Tartu Ülikooli eesti keele õppetooli toimetised 10). Tartu: Tartu Ülikool, lk 317-332.

Kelley, Page 1992. Biblical Hebrew. An Introductory Grammar. Michigan: William B. Eerdmans Publishing Company.

Kros s, Kristiina 1985. Heebrea keel algajatele. (EELK usuteaduste instituudi toimetised 1.) Tallinn.

Lill, Anne, Kanter, Maria, Ristikivi, Merike 2002. Studia Latina. Ladina keele õpik humanitaarerialade üliõpilastele. Tallinn: Eesti Keele Sihtasutus.

P r ill o p, Külli 2001. Georg Mülleri jutluste verbivormistik, Tartu (Käsikirjaline magistritöö. Tartu Ülikooli eesti keele õppetool).

P õ l d v e e, Aivar 2010. Bengt Gottfried Forselius ja tähed. Täiendusi vana kirjaviisi ja uue õppeviisi mõistmiseks. - Keel ja Kirjandus, nr 5, lk 331-352.

R a j a n d i, Henno 1999. Eesti impersonaali ja passiivi süntaks. (Eesti Keele Instituudi toimetised 3.) Tallinn: Eesti Keele Instituut.

R o s s, Kristiina 2006. Mida me teame keskaegsest vaimulikust eesti keelest? Eesti teoloogilise mõtlemise ajaloost: sissejuhatavaid märkusi ja apokrüüfe. Toim Riho Altnurme, Priit Rohtmets. Tartu: Tartu Ülikooli Kirjastus, lk 6-16.

R o s s, Kristiina. 2009. Kõige vanemast tartukeelsest piiblitõlkest. - Tartu Ülikooli Lõuna-Eesti keele- ja kultuuriuuringute keskuse aastaraamat. Toim Triin Iva, Sulev Iva, Mari Mets. Tartu: Tartu Ülikooli Lõuna-Eesti keele- ja kultuuriuuringute keskus, lk 11-26.

S t a h l, Heinrich 1637. Anführung zu der Esthnischen Sprach, auff Wolgemeinten Rath, und Bittliches Ersuchen. Revall: Druckts Chr. Reusner der älter.

T a fe n a u, Kai 2011. Diskussionen über die estnische Schriftsprache in der zweiten Hälfte des 17. Jahrhunderts: Argumente und Beispiele. - Linguistica Uralica XLVII, nr 2, lk 130-143.

T a m m, Epp 1991. Vanakreeka keele õpetus 1. Hääliku- ja vormiõpetus. Tartu: Tartu Ülikool.

Th or Helle, Anton 1732. Kurtzgefaßte Anweisung Zur Ehstnischen Sprache. Halle: Gedruckt bey Stephan Orban.

To r n - L e e s i k, Reeli 2009. The Voice System of Estonian. - Sprachtypologie und Universalienforschung 62 (1-2), lk 72-90.

U n t, Jaan 1998. Uue Testamendi kreeka keel algajaile. (EELK Usuteaduse Instituudi toimetised 10.) Tallinn: Logos.

W a l t k e, Bruce, O' C o n n or, Michael Patrick 1990. An Introduction to Biblical Hebrew Syntax. Winona Lake: Eisenbrauns. 


\section{Use of the Estonian Passive and Impersonal by 17th-18th Century Bible Translators}

Keywords: Estonian bible translation, literary language history, passive, impersonal

The first translators of the Estonian Bible had to cope with the fact that the Estonian language expresses passivity and impersonality differently from the source languages. During the long road to the first full Bible, the preferences of the translators changed a lot. An observation of 16 versions of the New Testament (NT) from the period 1632-1739 has revealed a decisive change in the late 17th century. Until then, the most popular construction was saama + passive past participle, and the impersonal forms of the Estonian verb were used modestly. The situation reversed in the 1680s: from that point on, impersonal forms became common and saama-constructions rare. In three versions of the Old Testament (OT) from the same period no such change occurred: all translators used less of passive and impersonal forms in their OT than in their NT. One of the possible explanations seems to be that the translators of the NT relied much more on the previous tradition, which had begun under the strong influence of Luther's German translation. The versions of the OT, however, were much closer to the Hebrew Tanakh. Some impersonal forms seem to have already been fixed in the Catholic era by the Latin Vulgate.

Annika Kilgi (b. 1981), MA, Tallinn University, Institute of the Estonian Language and Culture, lecturer and PhD student, annika.kilgi@tlu.ee 